\title{
Elasto-Plastic Creep Thermal Deformation Behavior of Multi-Story Steel Frames Designed by the Plastic Method
}

\author{
K. MIGITA and T. OKABE \\ Faculty of Engineering \\ University of Kumamoto \\ Kumamoto, Japan
}

F. FURUMURA, T. AVE, and W. J. KIM

Research Laboratory of Engineering Material

Tokyo Institute of Technology

Tokyo, Japan

ABSTRACT

In order to get the information about the thermal deformation behavior of multi-story steel frames for the development of fire safety design, 7-story 3-bay plastic designed steel frames are investigated numerically under the simplified temperature model of heated members.

The one-dimensional nonlinear finite element method has been applied to simulate the elasto-plastic creep thermal deformation behavior of steel frames subjected to high temperature.

Within the plane frame structural analysis based on the beam theory, various interesting aspects of the thermal deformation behavior of both aseismatic and non-aseismatic designed steel frames have been observed.

\section{INTRODUCTION}

It is very useful to perform the study on the behavior of multistory steel frames subjected to fire environment to develop a rational fire safety desj.gn method of steel buildings.

In the past, analytical studies on the elasto-plastic creep behavior of steel structures at elevated temperatures were carried out by Cheng W.C.1), by Harmaty T.Z.2), and by Furumura F.et a $.3,4)$. In these studies, especially in Refs. $(1,4)$, although there were no sufficient material data of structural steels at high temperature, the numerical analysis method itself was already established based on the theory of one-dimensional finite element method. Since the main purpose of these studies was to show the analytical method itself, adopted analytical examples were limited to the simple models such as single beams, columns and portal frames.

Recently, Furumura F. et al. have carried out the detailed experimental investigations on the creep behavior of the structural steel at elevated temperatures, and also have reported the exact steel material data at high temperatures in Refs. (5-9) which could sufficiently match with the accuracy of analytical methods itself. Therefore it can be said that now a systematic analytical study on the thermal deformation behavior of practical multi-story steel frames have been enabled to carry out, and it is necessary to make the useful data for the the fire safety design. 
The purpose of this paper is to find out the significant aspects of the thermal deformation behavior of steel frames at high temperatures and get useful data from the simulated response for the fire safety design of steel buildings.

\section{MODELS OF STMULATTON}

In this paper the steel frames designed by the plastic method are adopted for analytical examples. The load carrying capacity of example frames must be clarified at room temperature at least, and these can be estimated approximately by the simple plastic hinge theory.

\section{Design of Multi-Story Frames}

The adopted examples consist of two kind of frames, namely, the aseismatic designed frame and the non-aseismatic designed frame, the former is designed for both the gravity load and the combined loads and the later is designed for only the gravity load. At room temperature, the safety factor against gravity load will differ considerably between the two kinds of frames, therefore also at elevated temperature their behavior will show a large difference with each other.

As shown in Fig. 1, 7-story 3-bay steel frames have been designed under the condition of the uniformly distributed gravity load on the beams with the magnitude of $39 \mathrm{kN} / \mathrm{m}$. The load factors are shown in Table 1 and the design formulae for steel members in Ref.(10) were used. Also, in order to make the final desjgned member strength equal to the minimum necessary plastic moment which is determined from the design ultimate load, the continuously varying H-shape cross section proposed by $\mathrm{S}$. Igarashi et a1.11) was adopted. And $\mathrm{SS} 41$ stee1 (oyrt $=235(\mathrm{~N} / \mathrm{mm} 2)$, Ert $=206(\mathrm{kN} / \mathrm{mm} 2)$ ) was used as the frame members.

The following two plastic design methods were utilized.

(1) Design method for the gravity load condition : The beams are assumed to be failed by forming beam mechanisms for the gravity load condition and the plastic moments of the beams and the columns are determined to

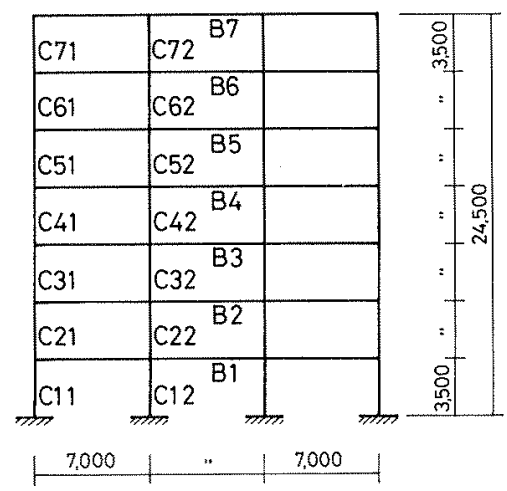

FIGURE 1. Frame geometry and symbols of members 


\begin{tabular}{c|c}
\hline Gravity Load Condition & $1.65(\mathrm{G}+\mathrm{P})$ \\
\hline Combined Load Condition & $\mathrm{G}+\mathrm{P}+1.5 \mathrm{~K}$ \\
\hline G: Dead Load $\mathrm{P}:$ Live Load $\mathrm{K}:$ Aseismatic Load
\end{tabular}

resist the required bending moments.

(2) Design method for the combined load condition : The aseismatic design method developed by S.Igarashi et al.11) is also used here.

Using either or both of the above two design methods, the following three types of steel frames were designed.

(A) B-Frame ... Non-aseismatic designed frames designed by method(1) for only the gravity load condition.

(B) P-Frame ... Aseismatic designed frames by both method(1) and (2) for both the gravity and the combined load conditions.

(C) 2P-Frame ... Aseismatic designed frames having same beams of P-Frame and twice bending strength columns of P-Frame.

B-Frame does not have the effect of the aseismatic design method on the load carrying capacity at all, and this is an idealized non-braced frame adjacent to braced frames in a bracing system building or a building standing within a non-seismatic country. P-Frame is an example model of the aseismatic designed frame with the story shear strength just equal to the design story shear strength. 2P-Frame is also an example model of the aseismatic designed frame, but this model has strong columns and relatively weak beams.

The safety factors of B-Frame members are just 1.65 for gravity load at room temperature, but the safety factors of P-Frame or 2P-Frame members are equal to or larger than 1.65 due to the effect of the aseismatic design.

The cross sections data of these frames are summarized in Table 2, where Rs shows the member strength ratio between B-Frame and P-Frame or 2P-Frame, and these ratios are calculated by the member design formulae in Ref.(10) for the gravity load mode. Except at the top story, Rs of PFrame and 2P-Frame members are about 2 or 10 times larger than those of B-Frame. Therefore the effect of the aseismatic design on the load carrying capacity of the members are very large.

In this paper, the total side-sway deformation of a frame due to the frame instability at high temperature is not treated, so the frame deformation is assumed to be symmetric, and only the left half part of a frame are selected for the analytical models, as shown in Fig. 2.

\section{Temperature Mode1 in Heated Members}

In order to investigate the basic response behavior of stee1 frames under simplified temperature conditions, a uniform temperature distribution and a linearly varying temperature history in members are assumed. And also to observe the residual deformation of the steel frames after heating, the numerical analysis has been carried out to the end of cooling process. As shown in Fig. 3, the model of temperature history of members is assumed to vary linearly from $20^{\circ} \mathrm{C}$ to $600^{\circ} \mathrm{C}$ in 
TABLE 2. Sectional dimensions of designed frames

\begin{tabular}{|c|c|c|c|c|c|c|c|}
\hline Frame & Member & Symb. & Sectiona1 Dimensions & $\mathrm{Zp}\left(\mathrm{cm}^{3}\right)$ & $\lambda$ & $\mathrm{P} / \mathrm{Py}$ & Rs \\
\hline \multirow{3}{*}{ B-FRAME } & \multirow{2}{*}{ Column } & $\begin{array}{l}\mathrm{C} 71 \\
\mathrm{C} 11 \\
\mathrm{C} 51 \\
\mathrm{C} 41 \\
\mathrm{C} 11 \\
\mathrm{C} 21 \\
\mathrm{C} 1 \mathrm{C}\end{array}$ & $\begin{array}{l}\mathrm{H}-22.50 \times 22.50 \times 1.08 \times 1.57 \\
\mathrm{H}-19.15 \times 19.15 \times 0.92 \times 1.34 \\
\mathrm{H}-20.17 \times 20.17 \times 0.97 \times 1.41 \\
\mathrm{H}-21.17 \times 21.17 \times 1.02 \times 1.48 \\
\mathrm{H}-22.15 \times 22.15 \times 1.07 \times 1.55 \\
\mathrm{H}-23.12 \times 23.12 \times 1.11 \times 1.62 \\
\mathrm{H}-24.06 \times 24.06 \times 1.16 \times 1.68\end{array}$ & $\begin{array}{r}842 \\
520 \\
607 \\
702 \\
804 \\
914 \\
1031\end{array}$ & $\begin{array}{l}36.5 \\
42.9 \\
40.7 \\
38.8 \\
37.1 \\
35.5 \\
34.2\end{array}$ & $\begin{array}{l}0.06 \\
0.17 \\
0.23 \\
0.28 \\
0.32 \\
0.36 \\
0.39\end{array}$ & \multirow{3}{*}{-} \\
\hline & & $\begin{array}{l}\mathrm{C} 2 \\
\mathrm{C} 2 \\
\mathrm{C} 52 \\
\mathrm{C} 2 \\
\mathrm{C} 2 \\
\mathrm{C} 2 \\
\mathrm{C} 2 \\
\mathrm{C} 2\end{array}$ & $\begin{array}{l}\mathrm{H}-11.80 \times 11.80 \times 0.57 \times 0.83 \\
\mathrm{H}-15.66 \times 15.66 \times 0.75 \times 1.10 \\
\mathrm{H}-18.65 \times 18.65 \times 0.90 \times 1.30 \\
\mathrm{H}-21.17 \times 21.17 \times 1.02 \times 1.48 \\
\mathrm{H}-23.40 \times 23.40 \times 1.13 \times 1.64 \\
\mathrm{H}-25.42 \times 25.42 \times 1.22 \times 1.78 \\
\mathrm{H}-27.27 \times 27.27 \times 1.31 \times 1.91\end{array}$ & $\begin{array}{r}122 \\
284 \\
480 \\
702 \\
948 \\
1215 \\
1500\end{array}$ & $\begin{array}{l}69.6 \\
52.5 \\
44.1 \\
38.8 \\
35.1 \\
32.3 \\
30.1\end{array}$ & $\begin{array}{l}0.46 \\
0.52 \\
0.55 \\
0.57 \\
0.58 \\
0.59 \\
0.60\end{array}$ & \\
\hline & Bean & $\begin{array}{l}B 7 \\
B 6 \\
B 5 \\
B 4 \\
B 3 \\
B 2 \\
B 1\end{array}$ & $\begin{array}{l}\mathrm{H}-33.56 \times 16.78 \times 0.77 \times 1.21 \\
\mathrm{H}-33.56 \times 16.78 \times 0.77 \times 1.21 \\
\mathrm{H}-33.56 \times 16.78 \times 0.77 \times 1.21 \\
\mathrm{H}-33.56 \times 16.78 \times 0.77 \times 1.21 \\
\mathrm{H}-33.56 \times 16.78 \times 0.77 \times 1.21 \\
\mathrm{H}-33.56 \times 16.78 \times 0.77 \times 1.21 \\
\mathrm{H}-33.56 \times 16.78 \times 0.77 \times 1.21\end{array}$ & $\begin{array}{l}842 \\
842 \\
842 \\
842 \\
842 \\
842 \\
842\end{array}$ & $\begin{array}{l}50.2 \\
50.2 \\
50.2 \\
50.2 \\
50.2 \\
50.2 \\
50.2\end{array}$ & - & \\
\hline \multirow{3}{*}{ P-FRAME } & \multirow{2}{*}{ Column } & $\begin{array}{l}\mathrm{C} 71 \\
\mathrm{C} 61 \\
\mathrm{C} 51 \\
\mathrm{C} 41 \\
\mathrm{C} 31 \\
\mathrm{C} 21 \\
\mathrm{C} 11\end{array}$ & $\begin{array}{l}\mathrm{H}-22.50 \times 22.50 \times 1.08 \times 1.57 \\
\mathrm{H}-25.40 \times 25.40 \times 1.22 \times 1.78 \\
\mathrm{H}-28.36 \times 28.36 \times 1.36 \times 1.98 \\
\mathrm{H}-30.56 \times 30.56 \times 1.47 \times 2.14 \\
\mathrm{H}-32.42 \times 32.42 \times 1.56 \times 2.27 \\
\mathrm{H}-34.18 \times 34.18 \times 1.65 \times 2.39 \\
\mathrm{H}-36.04 \times 36.04 \times 1.73 \times 2.52\end{array}$ & $\begin{array}{l}842^{*} \\
1213 \\
1687 \\
2111 \\
2520 \\
2955 \\
3464\end{array}$ & $\begin{array}{l}36.5 \\
32.4 \\
29.0 \\
26.9 \\
25.4 \\
24.0 \\
22.8\end{array}$ & $\begin{array}{l}0.06 \\
0.10 \\
0.12 \\
0.14 \\
0.15 \\
0.17 \\
0.17\end{array}$ & $\begin{array}{l}1.00 \\
2.48 \\
3.20 \\
3.64 \\
3.95 \\
4.23 \\
4.55\end{array}$ \\
\hline & & $\begin{array}{l}\mathrm{C} 72 \\
\mathrm{C} 62 \\
\mathrm{C} 52 \\
\mathrm{C} 42 \\
\mathrm{C} 32 \\
\mathrm{C} 22 \\
\mathrm{C} 12\end{array}$ & $\begin{array}{l}\mathrm{H}-28.02 \times 28.02 \times 1.35 \times 1.96 \\
\mathrm{H}-31.60 \times 31.60 \times 1.52 \times 2.21 \\
\mathrm{H}-34.82 \times 34.82 \times 1.68 \times 2.44 \\
\mathrm{H}-37.00 \times 37.00 \times 1.78 \times 2.59 \\
\mathrm{H}-38.67 \times 38.67 \times 1.86 \times 2.71 \\
\mathrm{H}-40.19 \times 40.19 \times 1.93 \times 2.81 \\
\mathrm{H}-41.80 \times 41.80 \times 2.01 \times 2.92\end{array}$ & $\begin{array}{l}1628 \\
2336 \\
3124 \\
3747 \\
4279 \\
4803 \\
5404\end{array}$ & $\begin{array}{l}29.3 \\
26.0 \\
23.6 \\
22.2 \\
21.3 \\
20.5 \\
19.7\end{array}$ & $\begin{array}{l}0.08 \\
0.13 \\
0.16 \\
0.19 \\
0.21 \\
0.24 \\
0.25\end{array}$ & $\begin{array}{l}7.40 \\
4.71 \\
3.80 \\
3.22 \\
2.82 \\
2.54 \\
2.35\end{array}$ \\
\hline & Beam & $\begin{array}{l}\text { B7 } \\
\text { B6 } \\
\text { B5 } \\
\text { B4 } \\
\text { B3 } \\
\text { B2 } \\
\text { B1 }\end{array}$ & $\begin{array}{l}\mathrm{H}-33.56 \times 16.78 \times 0.77 \times 1.21 \\
\mathrm{H}-44.58 \times 22.29 \times 1.02 \times 1.61 \\
\mathrm{H}-49.22 \times 24.61 \times 1.13 \times 1.77 \\
\mathrm{H}-52.54 \times 26.27 \times 1.20 \times 1.89 \\
\mathrm{H}-54.71 \times 27.35 \times 1.25 \times 1.97 \\
\mathrm{H}-56.40 \times 28.20 \times 1.29 \times 2.03 \\
\mathrm{H}-58.10 \times 29.05 \times 1.33 \times 2.09\end{array}$ & $\begin{array}{l}842^{*} \\
1973 \\
2657 \\
3232 \\
3649 \\
3998 \\
4370\end{array}$ & $\begin{array}{l}50.2 \\
37.8 \\
34.2 \\
32.1 \\
30.8 \\
29.9 \\
29.0\end{array}$ & - & $\begin{array}{l}1.00 \\
2.34 \\
3.16 \\
3.84 \\
4.33 \\
4.75 \\
5.19\end{array}$ \\
\hline \multirow{3}{*}{ 2P-FRAME } & \multirow{2}{*}{ Colunin } & $\begin{array}{l}C 71 \\
C 61 \\
C 51 \\
C 41 \\
C 31 \\
C 21 \\
C 11\end{array}$ & $\begin{array}{l}\mathrm{H}-28.34 \times 28.34 \times 1.36 \times 1.98 \\
\mathrm{H}-32.00 \times 32.00 \times 1.54 \times 2.24 \\
\mathrm{H}-35.73 \times 35.73 \times 1.72 \times 2.50 \\
\mathrm{H}-38.50 \times 38.50 \times 1.85 \times 2.69 \\
\mathrm{H}-40.84 \times 40.84 \times 1.97 \times 2.86 \\
\mathrm{H}-43.07 \times 43.07 \times 2.07 \times 3.01 \\
\mathrm{H}-45.41 \times 45.41 \times 2.19 \times 3.18\end{array}$ & $\begin{array}{l}1684 \\
2425 \\
3374 \\
4222 \\
5041 \\
5910 \\
6928\end{array}$ & $\begin{array}{l}29.0 \\
25.7 \\
23.0 \\
21.4 \\
21.1 \\
19.1 \\
18.1\end{array}$ & $\begin{array}{l}0.04 \\
0.06 \\
0.08 \\
0.09 \\
0.10 \\
0.10 \\
0.11\end{array}$ & $\begin{array}{l}2.00 \\
4.96 \\
6.39 \\
7.40 \\
8.18 \\
8.88 \\
9.65\end{array}$ \\
\hline & & $\begin{array}{l}\mathrm{C} 72 \\
\mathrm{C} 62 \\
\mathrm{C} 52 \\
\mathrm{C} 42 \\
\mathrm{C} 32 \\
\mathrm{C} 22 \\
\mathrm{C} 11\end{array}$ & $\begin{array}{l}\mathrm{H}-35.31 \times 35.31 \times 1.70 \times 2.47 \\
\mathrm{H}-39.82 \times 39.82 \times 1.92 \times 2.79 \\
\mathrm{H}-43.88 \times 43.88 \times 2.11 \times 3.07 \\
\mathrm{H}-46.61 \times 46.61 \times 2.24 \times 3.26 \\
\mathrm{H}-48.72 \times 48.72 \times 2.34 \times 3.41 \\
\mathrm{H}-50.64 \times 50.64 \times 2.44 \times 3.54 \\
\mathrm{H}-52.67 \times 52.67 \times 2.53 \times 3.69\end{array}$ & $\begin{array}{r}3256 \\
4671 \\
6249 \\
7493 \\
8558 \\
9607 \\
10809\end{array}$ & $\begin{array}{l}23.3 \\
20.6 \\
18.7 \\
17.7 \\
16.9 \\
16.2 \\
15.6\end{array}$ & $\begin{array}{l}0.05 \\
0.08 \\
0.10 \\
0.12 \\
0.14 \\
0.15 \\
0.16\end{array}$ & $\begin{array}{r}11.74 \\
7.47 \\
6.05 \\
5.12 \\
4.47 \\
4.03 \\
3.74\end{array}$ \\
\hline & Beam & $\begin{array}{l}\text { B7 } \\
\text { B6 } \\
B 5 \\
B 4 \\
B 3 \\
B 2 \\
B 1\end{array}$ & $\begin{array}{l}\mathrm{H}-33.56 \times 16.78 \times 0.77 \times 1.21 \\
\mathrm{H}-44.58 \times 22.29 \times 1.02 \times 1.61 \\
\mathrm{H}-49.22 \times 24.61 \times 1.13 \times 1.77 \\
\mathrm{H}-52.54 \times 26.27 \times 1.20 \times 1.89 \\
\mathrm{H}-54.71 \times 27.35 \times 1.25 \times 1.97 \\
\mathrm{H}-56.40 \times 28.20 \times 1.29 \times 2.03 \\
\mathrm{H}-58.10 \times 29.05 \times 1.33 \times 2.09\end{array}$ & $\begin{array}{l}842^{*} \\
1973 \\
2657 \\
3232 \\
3649 \\
3998 \\
4370\end{array}$ & $\begin{array}{l}50.2 \\
37.8 \\
34.2 \\
32.1 \\
30.8 \\
29.9 \\
29.0\end{array}$ & - & $\begin{array}{l}1.00 \\
2.34 \\
3.16 \\
3.84 \\
4.33 \\
4.75 \\
5.19\end{array}$ \\
\hline
\end{tabular}

$Z_{p}$ : plastic section modulus $\lambda$ : slenderness ratio $P$ : column load Py : yield load of column Rs : member strength ratio between B-Frame and P-Frame ; $2 \mathrm{P}$-Frame 


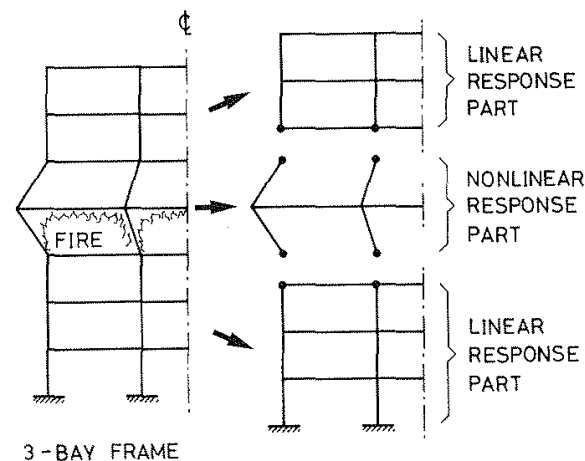

FIGURE 2. Condensation technique for linear response parts

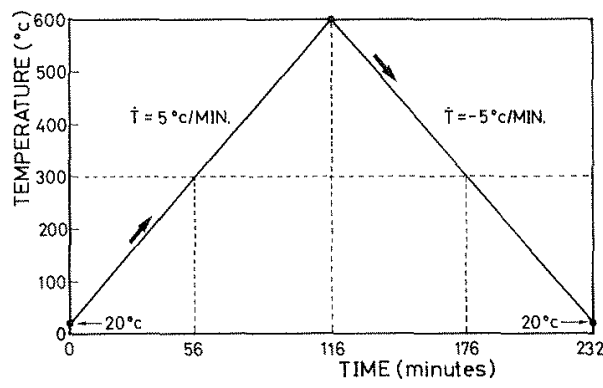

FIGURE 3. Temperature history model of example frames

both heating and cooling process with a temperature varying rate of $5^{\circ} \mathrm{C}$ per minute.

For the purpose of studying the variation of the load carrying capacity for the different story in the case of fire, the 1-st, 4-th and 7 -th story are subjected to heat and studied individually. A11 analytical examples are summarized in Table 3.

\section{METHOD OF ANALYSIS}

In this paper, the one-dimensional finite element nonlinear numerical analysis method, which was developed by Furumura F.et al. in Ref.(4), has been applied to simulate the elasto-plastic creep thermal deformation behavior of steel frames subjected to a fire environment. The members of a steel frames, such as columns and beams, are assumed to be of such type that the usual beam theory is applicable. The bending deformation and the axial deformation are considered but the shearing deformation is neglected. Also, these members are subdivided into inite subelements in order to evaluate the effect of the plastic zone 


\begin{tabular}{c|c|c|c|c}
\hline \multicolumn{2}{c|}{$\begin{array}{c}\text { Designed } \\
\text { Frame }\end{array}$} & B-Frame & P-Frame & 2P-Frame \\
\hline \multicolumn{2}{c|}{ Bay } & 3 & 3 & 3 \\
\hline \multirow{3}{*}{$\begin{array}{l}\text { Heated } \\
\text { story }\end{array}$} & 4 & B34 & P34 & 2 P34 \\
\cline { 2 - 5 } & 1 & B31 & P31 & 2P31 \\
\hline
\end{tabular}

spread toward the member axis direction and the additional moment due to the axial force. This method will be the most effective one to simulate the behavior of steel frames in fire accurately and concretely within the time and storage limitations of currently available computers.

The following improvements are added to this method. (1) As the constitutive laws of SS41 steel, the mechanical model of the elato-plastic creep behavior proposed in Ref.(8), the uniaxial stressstrain relationship presented in Ref.(9), and the creep strain expression shown in Ref.(5) are used. The expression of the thermal elongation strain in Ref.(4) is also used in this paper.

(2) As shown in Fig. 2, if only a part of the framed structure is heated by the fire environment, the large deformation will be limited within the vicinity of the fire compartment, and the deformation of other members will remain almost within the elastic range. Therefore, also as illustrated in Fig. 2, for the purpose of economizing the computational cost, the framed structure is separated into the nonlinear response part and the linear response parts. And the behavior of the later parts are assumed to obey the linear theory. The nonlinear analysis method is applied only to the nonlinear response parts.

The stiffness matrix and the external load vector of linear response parts can be easily transformed into the equivalent stiffness matrix and the equivalent external load vector in terms of nodes connecting the two parts by using the condensation technique. And by assembling these matrices and other member stiffness matrices in the usual manner, the following incremental equilibrium equation is obtained.

$\left(\mathrm{K}+\mathrm{Ko}_{0}\right) \cdot \Delta \mathrm{U}=\mathrm{Fex}-\mathrm{Fin}+\left(\mathrm{Fo}_{\mathrm{O}}-\mathrm{Ko} \cdot \mathrm{U}\right)$

where $K=$ the tangent stiffness matrix of the nonlinear response part, $\mathrm{K}_{\mathrm{O}}=$ the equivalent stiffness matrix of the linear response part, $\Delta \mathrm{U}=$ the incremental nodal displacement vector of the nonlinear response part, Fex=the external force vector of the nonlinear response part, Fin=the internal force vector of the nonlinear response part, Fo=the equivalent external load vector of the linear response part, and $U=$ the nodal displacement vector of the nonlinear response part.

The practical comparison between the response of the above model and the response of the total frame nonlinear analysis is not shown here, but there was a very good agreement between them. Therefore the above technique is adequately effective for the examples used in this paper. 
(3) Applying the sub-structures concept to the subelements in series within a nember, the member stiffness matrix in terms of the

displacement at both ends of a member are derived. The cross section of a member is divided into 10 subslices, the column and the interior beams are divided into 10 subelements, and the exterior beams are divided into 20 subelements respectively.

(4) For temperature under $500^{\circ} \mathrm{C}$, time increment $1 / 32$ minute is used. While for temperature over $500^{\circ} \mathrm{C}$ or as soon as the displacements varying rate begin to increase, the time increment $1 / 128$ minute is used.

\section{NUMERTCAL RESULT AND DTSCUSSION}

The numerical results of all examples have been classified into the following three groups according to their behaviors.

\section{Top Story Heated Cases (B37,P37, 2P37)}

The midpoint deflections and thermal expansions of the heated beams are shown in Fig. 4. Since the members at the top story of frames have the tendency to be designed against the gravity load condition, and the safety factor of these members are just 1.65 against the working gravity load in room temperature, the heated beams in this group deflect largely and collapse at about $550^{\circ} \mathrm{C}$, as shown in $\mathrm{Fig} \cdot 4$.

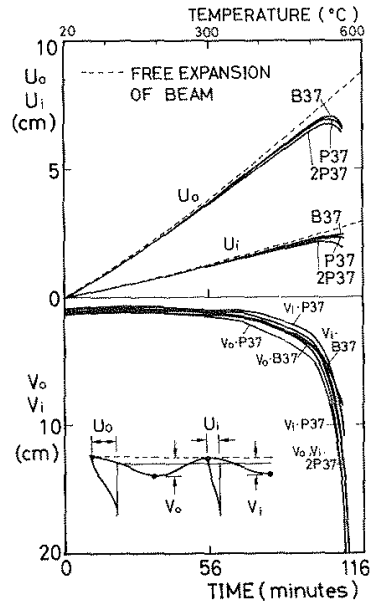

FTGURE 4. Deflection and expansion histories of heated beams in top story heated examples (B37, P37, 2P37)

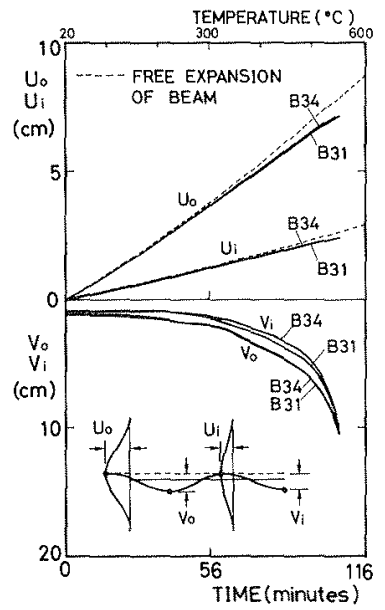

FIGURE 5. Deflection and expansion histories of heated beams in B31, B34 


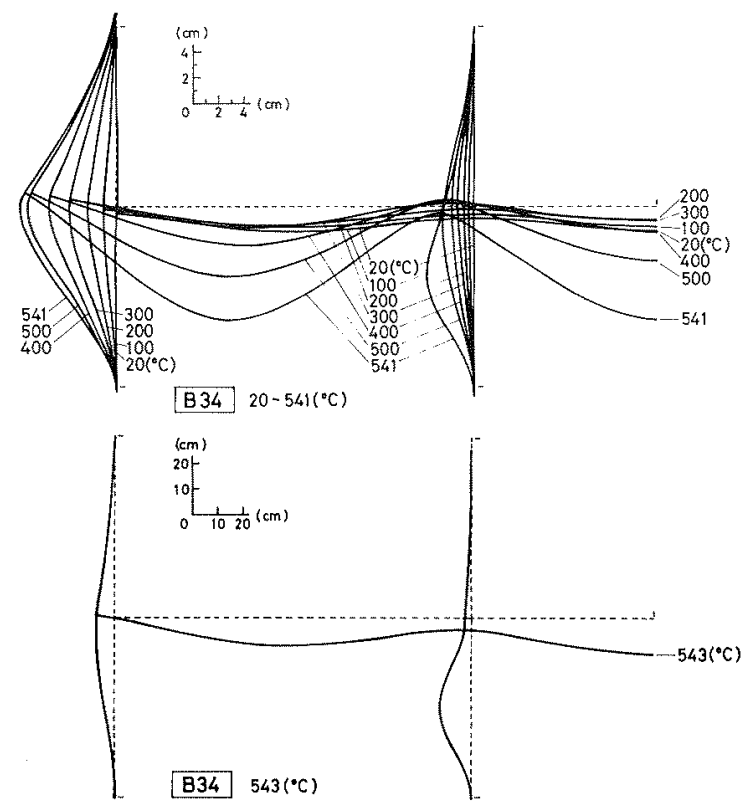

FTGURE 6. Deformation histories of B34

The Case of B-Frame with 1-st and 4-th Story Heated (B31, B34)

The time histories of deflection and expansion of heated beams and the deformation histories are shown in Figs. 5 and 6 , respectively. A1so in this case, the large deflection of heated beams are observed at about $540^{\circ} \mathrm{C}$ as described in Fig. 5. But the deformation modes of the heated interior columns begin to change at about $520^{\circ} \mathrm{C}$ from the double curvature type to the fixed end bowing type, and finally the large deformations of the interior columns cause the overall frame collapse. Therefore in this case it has been shown that columns designed as a centra11y loaded compression member are considerably dangerous against the fire heating.

The Cases of P-Frame and 2P-Frame with 1-st or 4-th Story Heated (P31,P34,2P31, 2P34)

The deformation histories of 2P34, the deflections and expansions of heated beams are shown in Figs. 7 and 8 ,respectively. The typical deformation behaviors caused by the thermal stress are observed in Fig. 7. The midpoint deflections of interior beams, $V i$ are larger than those of exterior beams, Vo. Since the columns of 2P-Frame have larger stiffness and plastic moment than those of P-Frame, in 2P-Frame the restriction forces of columns against the thermal expansions of beams are larger. Therefore, the heated beams of $2 \mathrm{P}$-Frame tend to buckle at high temperature due to the thermal axial forces as shown in Figs. 7 and 8. The thermal expansion of the heated beam attains to about $7 \mathrm{~cm}$ at $600^{\circ} \mathrm{C}$. 

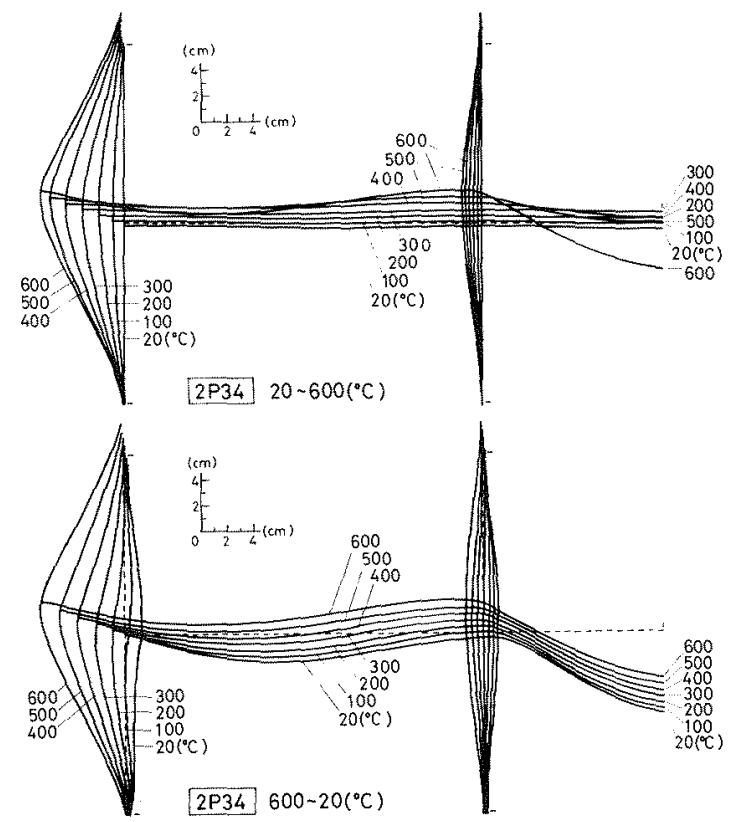

FIGURE 7. Deformation histories of 2P34
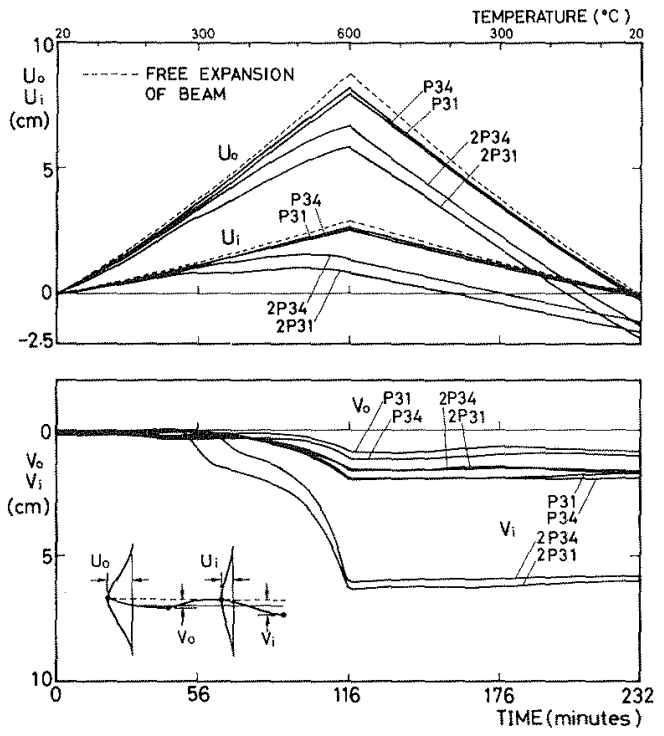

FIGURE 8. Deflection and expansion histories of heated beams in P31, P34,2P31,2P34 
Under the simplified temperature model of heated members, the response of 7 -story 3 -bay steel frames designed by the plastic method have been analyzed, and the various aspects on the thermal deformation behavior of steel frames are observed. These knowledge will contribute to the development of a rational fire safety design procedure of steel frames. But as these results have been depended on a simplified temperature condition model and on a few idealized steel frame models only, so it is necessary to proceed these research with a more realistic temperature models on many more steel frame models, and to accumulate more data.

\section{REFERENCES}

1. Cheng.W.C., Mak.C.K., "Computer Analysis of Steel Frame in Fire", J. of the Structural Division, ASCE, Vo1.101, No.ST4,1975, pp858-867.

2. Harmathy.T.Z., "Creep Deflection of Meta1 Beams in Transient Heating Process, with Particular Reference to Fire", CAN.J.CIV.ENG. ,Vo1.3, 1976, pp.219-228.

3. Furumura,F. and Shinohara, Y., "Inelastic Behavior of Protected Stee1. Columns in Fire", IABSE Congress, Japan, Final. Report, 1976.9,pp.193 -198 .

4. Furumura, F. and Shinohara,Y., "Inelastic Behavior of Protected Steel Beams and Frames in Fire", Trans. of A.I.J. , No.300, February 1981 , pp. 141-149.

5. Fujimoto,M.,Furumura,F., Ave, T. and Shinohara, Y., "Prinary Creep of Structural Steel(SS41) at High Temperatures", Trans. of A.I.J., No.296, October 1980,pp.145-157.

6. Fujimoto,M., Furumura,F. and Ave,T.,"Effect of Step-wise Change of Stress on Primary Creep of Structural Steel",Trans. of A.I.J., No.308, October 1981, pp.165-173.

7. Furumura,F. and Ave, T., "Effect of Step-wise Change of Temperature on Primary Creep of Structura1 Steel", Trans. of A.I.J., No.339, May 1984, pp. 165-173.

8. Furumura,F., Ave, T. Kim, W.J. and Okabe, T., "Nonlinear Elasto-plastic Creep Behavior of Structural Steel under Continuously Varying Stress and Temperature",J. of Structural and Construction Engineering, Trans, of A.I.J. , No.353, July 1985, pp.92-102.

9. Furumura,F.,Ave,T.,Okabe,T. and Kim, W, J., "A Uniaxial Stress-Strain Formula of Structural Steel at High Temperature and its Application to Thermal Deformation Analysis of Steel Frames",J. of Structural and Construction Engineering, Trans. of A.I.J., No.363, May 1986,pp.110 -117 .

10. Architectural Institute of Japan, "Recommendations for the plastic design of Steel Structures", 1975.

11. Igarashi,S. and Ogawa,K.,"A Study on the Kinematic Model of Steel Frames for Aseismic Design. Part 1. Effect of Vertical Ground Motion on the Seismic Response", Trans. of A.I.J., No.260, june 1978, pp. $77-85$. 